\title{
PERFORMANCE OF HIGH POWER LIGHT EMITTING DIODE FOR VARIOUS ZINC OXIDE FILM THICKNESS AS THERMAL INTERFACE MATERIAL
}

\author{
Subramani Shanmugan ${ }^{1}$, Devarajan Mutharasu², Haslan Abu Hassan ${ }^{3}$ \\ ${ }^{1,2,3}$ Nano Optoelectronics Research Laboratory, School of Physics, Universiti Sains Malaysia (USM), Minden, Pulau \\ Pinang, 11800, Malaysia, shagan77in@yahoo.co.in
}

\begin{abstract}
Oxide ceramic materials have attractive features either as filler or substrate materials in electronic packaging. Consequently, ZnO thin film for various thicknesses was prepared over Al substrates by RF sputtering and used as heat sink for high power LED. The thermal transient curve of device under test (DUT) was recorded for five boundary conditions. Rise in junction temperature $\left(T_{J}\right)$ was measured and observed low value $\left(54.4^{\circ} \mathrm{C}\right)$ for $200 \mathrm{~nm} \mathrm{ZnO}$ thin films at $350 \mathrm{~mA}$. The difference in junction temperature rise $\left(\Delta T_{J}\right)$ was observed as $7.46^{\circ} \mathrm{C}$ at $700 \mathrm{~mA}$ when compared to bare Al substrates. The total thermal resistance $\left(R_{\text {th-tot }}\right)$ of the DUT was low for $200 \mathrm{~nm} \mathrm{ZnO}$ thin film coated Al substrates. AFM images were used to evaluate the surface roughness factors and their influence on thermal resistance. As expected, the surface roughness, grain size and peak-valley distance were strongly influenced the heat flow.
\end{abstract}

Index Terms: ZnO thin film, thermal interface material, LED, thermal resistance, surface roughness

\section{INTRODUCTION}

Surface irregularities play a controlling part in the behavior of the interface and may create thermal contact resistance as a result of air gaps occupied at irregular surface. This could be avoided and achieved good thermal contact conductance by means of filling the air gap using thermally conductive materials. As predicted, in all cases, the thermal resistance follows a straight line as a function of bond line thickness (BLT). Thermal conductivity of the bulk material is well determined by this method [1].

Nitride and oxide based materials have been suggested for thermal interface materials and thermal paste (TP) type TIM has been mostly used for all electronic packaging applications for ease of use. Though they have been employed extensively as dielectric materials in printed circuit board technology for effective heat dissipation, the synthesis processes of these nitride and oxide based ceramic coated substrates are a significant drawback as these raw materials are costly [2]. Zinc oxide is a II-VI compound semiconductor with wide band gap $(\sim 3: 37 \mathrm{eV})$, by which it has been recognized as a promising photonic material in the ultraviolet (UV) region. $\mathrm{ZnO}$ is very abundant in nature, has high thermal and chemical stability [3].

$\mathrm{Xu}$ et al., also reported that out of all the commercial thermal interface materials studied, the $\mathrm{ZnO}$ filled silicone of Dow Corning gives the highest thermal contact conductance [4]. $\mathrm{ZnO}$ is also considered as a promising candidate for $\mathrm{GaN}$ epitaxy as substrate mainly due to the fact that the lattice mismatch between $\mathrm{GaN}$ and $\mathrm{ZnO}$ is very small compared to that with the most commonly used substrate, sapphire. The convincing thermal conductivity $(1-1.2 \mathrm{~W} / \mathrm{mK})$ and low thermal expansion coefficient of wurzite $\mathrm{ZnO}$ [5] increases the avenues of this material to be engineered into interesting hints at new electronic applications down the road. The surface quality plays a crucial role on thermal contact resistance and defines the thermal conductivity considerably. Surface roughness (finish) is defined as the average deviation from the mean surface height. In general for very low thermal resistance, a surface finish in the range of $1.27-1.5 \mu \mathrm{m}$ is recommended [6].

A research demonstrated that the surface roughness between $0.4 \mu \mathrm{m}$ and $1.63 \mu \mathrm{m}$ in the presence of TIM resulted in less than a $2.5 \%$ difference in interface thermal resistance [7]. In our knowledge, thin film has not been reported as thermal interface material especially $\mathrm{ZnO}$. We have also prepared AlN thin film as thermal interface materials in another work [8] and achieved good results in contact conductance. In another study, two different thickness of $\mathrm{ZnO}$ were tested as thermal interface material and achieved good results where the influence of surface parameters has not been addressed [9].

Accurate measurement of bond line thickness is necessary in order to achieve precise bond line thickness control. A conventional bond line thickness measurement method is cross-sectioning, which requires a cured die to be cut open 
along a line. Generally, a thin bond line is preferred over a thick one, since the stress concentration at the corners of the joint is lesser in a thinner bond line. Also, the air cavity concentration is lesser in a thin bond line as compared to a thick one. Consequently, three different thicknesses of $\mathrm{ZnO}$ thin film are used as thermal interface material and the influence of their thickness and surface parameters on the thermal resistance of given LED are tested.

\subsection{Theoretical Background}

The device junction temperature in the test condition can be determined by

$$
T_{J}=T_{J 0}+\Delta T_{J}
$$

Where $T_{J 0}=$ initial device junction temperature $\left({ }^{\circ} \mathrm{C}\right), \Delta T_{J}=$ change in junction temperature due to heater power application $\left({ }^{\circ} \mathrm{C}\right)$. Static mode was applied using still air box for all measurement, which applies heating power to the DUT on a continuous basis while the $T_{J}$ was monitored through measurement of temperature-sensitive parameter. The thermal contact conductance for joint between contacting solids is defined as

$$
h_{c}=\frac{Q / A}{\Delta T}=\frac{Q / A}{T_{1}-T_{2}}=\frac{Q}{A\left(T_{1}-T_{2}\right)}
$$

Where $T_{1}$ and $T_{2}$ are the temperatures of the bounding surfaces of the contact, and $Q / A$ is the heat flow per unit area [10]. The effective total thermal resistance at the interface between two materials is a sum of the resistance due to the thermal conductivity of the TIM and contact resistance between the TIM and the two contacting surfaces (see fig.1). This is generally expressed as [11].

$$
R_{\text {effective }}=\left(B L T / k_{\mathrm{TIM}} \mathrm{A}\right)+R_{\mathrm{c} 1}+R_{\mathrm{c} 2}
$$

Where, $B L T$ and $k_{T I M}$ are the bond line thickness and thermal Conductivity of the interface material respectively and $A$ is the area. $R_{c 1}$ and $R_{c 2}$ are contact resistances of the TIM at the boundary with the two surfaces and illustrated schematically in Fig. 1a. In this study, the prepared thin film thickness is considered as bond line thickness.
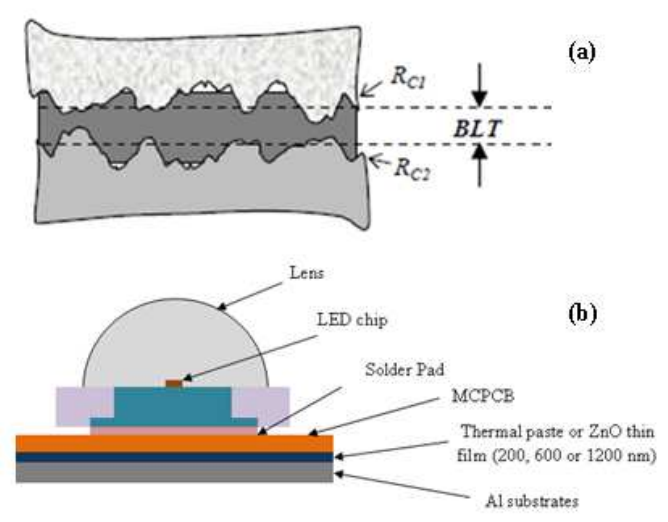

Fig-1 (a) Thermal interface material inserted between the two contacting bodies where $R_{c l}$ and $R_{c 2}$ are contact resistances of the TIM at the boundary with the two surfaces and (b) Schematic illustration of LED employed thermal paste or $\mathrm{ZnO}$ thin film as thermal interface material

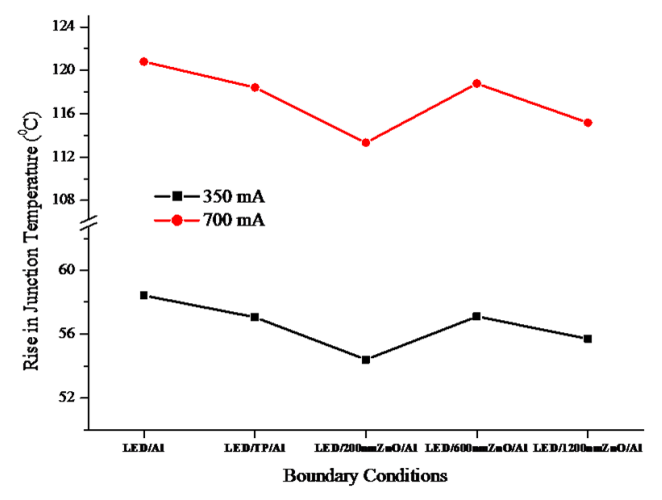

Fig2. Rise in junction temperature of $3 \mathrm{~W}$ green LED for five different boundary conditions measured at 350 and $700 \mathrm{~mA}$.

\section{EXPERIMENTAL WORK}

\subsection{ZnO Thin Film Synthesis}

The synthesis of $\mathrm{ZnO}$ thin film has already been reported in another work by the same author [9]. Briefly, ZnO (99.99\% purity) target was used in $\mathrm{RF}$ sputtering for $\mathrm{ZnO}$ thin film coating on $\mathrm{Al}$ substrates $(23 \mathrm{~cm}$ x $25 \mathrm{~cm} \times 1.5 \mathrm{~cm})$ which were used as heat sink. High pure $\operatorname{Ar}(99.999 \%)$ was used as sputtering gas. Initially, the chamber pressure was pumped down to $8.5 \times 10^{-6}$ mbar after loading the ultrasonically cleaned substrates into the chamber. Pre-sputtering was carried out to remove the surface oxidation of the target without opening the source shutter. All coatings were made in $150 \mathrm{~W}$ RF power at chamber pressure of $6.61 \times 10^{-3}$. The $\mathrm{ZnO}$ thin film was prepared in three different film thicknesses (200, 600 and $1200 \mathrm{~nm}$ ). The surface morphology of the prepared $\mathrm{ZnO}$ thin film was also tested using atomic force spectroscopy 
(AFM) (model: ULTRA Objective, Surface Imaging Systems, $\mathrm{GmbH})$ in the non-contact mode.

\subsection{Thermal Transient Analysis}

The thermal performance of prepared $\mathrm{ZnO}$ thin film as interface material was tested and thermal transient curve was captured for the given LED based on the electrical test method JEDEC JESD-51. The high power (3W green) LED package attached with Metal Core Printed Circuit Board (MCPCB) was fixed on bare $\mathrm{Al}$ substrate (without and with thermal paste) and $\mathrm{ZnO}$ thin film $(200,600$ and $1200 \mathrm{~nm})$ coated $\mathrm{Al}$ substrates (see fig.1b) and carried out the experiment using Thermal Transient Tester (T3Ster) in still air box. For comparison, the thermal behavior of given LED with thermal paste condition was also tested where cooler master thermal paste kit was used as thermal interface material. The thermal transient analysis was carried out for the given LED at three different currents $100 \mathrm{~mA}, 350 \mathrm{~mA}$ and $700 \mathrm{~mA}$ at room temperature. The current densities were calculated as 0.961 $\mathrm{A} / \mathrm{mm}^{2}, 3.37 \mathrm{~A} / \mathrm{mm}^{2}$ and $6.75 \mathrm{~A} / \mathrm{mm}^{2}$ respectively. After the LED was forward biased for 900 s, the transient cooling curve of heat flow was captured for another 900s. To confirm the repeatability/ reproducibility, the experiment was repeated for 3 times. The obtained cooling profile of the LED for uncoated and different thicknesses of $\mathrm{ZnO}$ thin film coated $\mathrm{Al}$ substrates was processed for structure functions using T3ster Master Software.

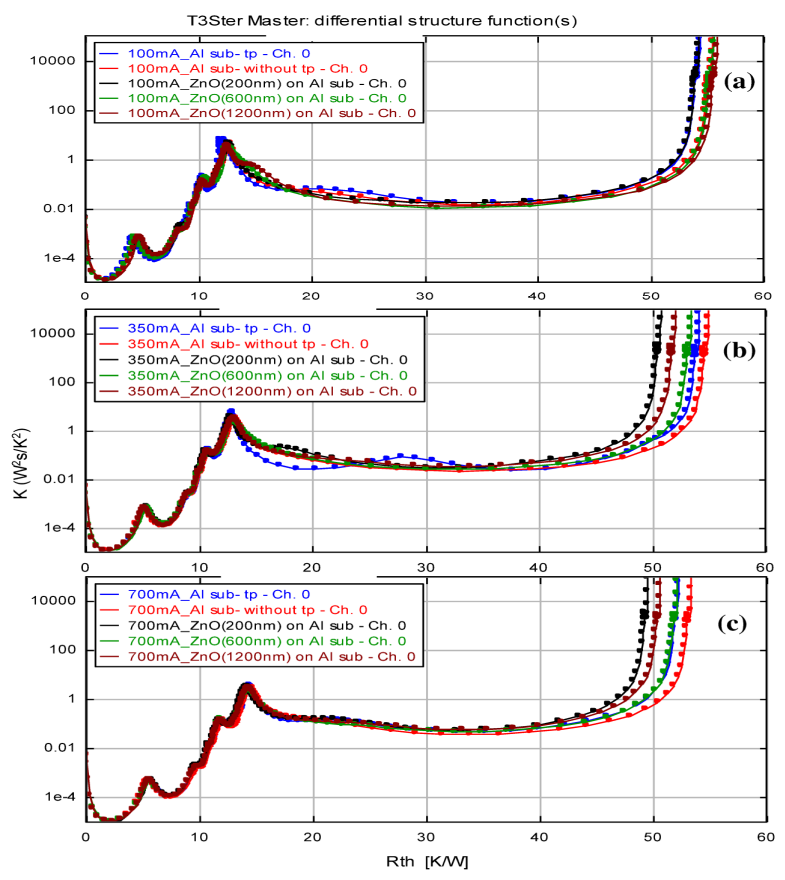

Fig3. Differential structure function of $3 \mathrm{~W}$ green LED for five different boundary conditions recorded at (a) 100, (b) 350 and (c) $700 \mathrm{~mA}$

\section{RESULTS AND DISCUSSION}

\subsection{Thermal Resistance Analysis}

The transient cooling curve for all samples is recorded and the observed raise in junction temperature is given in Fig. 2. Since the $\Delta T_{J}$ for $100 \mathrm{~mA}$, we didn't discuss the results here. But a noticeable decrease in $T_{J}$ could be observed at and above 350 $\mathrm{mA}$ driving currents for $\mathrm{ZnO}$ thin film interface. It reveals that the rise in $T_{J}$ shows very low for $200 \mathrm{~nm} \mathrm{ZnO}$ thin film coated substrates and the $\Delta T_{J}$ between bare and $200 \mathrm{~nm} \mathrm{ZnO}$ thin film samples show low value $\left(\Delta T_{J}=7.46{ }^{\circ} \mathrm{C}\right.$ at $\left.700 \mathrm{~mA}\right)$ than other thicknesses.

Table1: Total thermal resistance of $3 \mathrm{~W}$ green LED at five boundary conditions

\begin{tabular}{|l|c|c|c|}
\hline \multicolumn{4}{|c|}{ Total Thermal resistance $(\mathrm{K} / \mathrm{W})$} \\
\hline Boundary conditions & $100 \mathrm{~mA}$ & $350 \mathrm{~mA}$ & $700 \mathrm{~mA}$ \\
\hline $\mathrm{LED} / \mathrm{Al}$ & 55.43 & 54.90 & 53.31 \\
\hline $\mathrm{LED} / \mathrm{TP} / \mathrm{Al}$ & 54.32 & 54.08 & 52.16 \\
\hline $\mathrm{LED} / \mathrm{ZnO}(200 \mathrm{~nm}) / \mathrm{Al}$ & 54.20 & 50.67 & 49.46 \\
\hline $\mathrm{LED} / \mathrm{ZnO}(600 \mathrm{~nm}) / \mathrm{Al}$ & 55.51 & 53.31 & 52.09 \\
\hline $\mathrm{LED} / \mathrm{ZnO}(1200 \mathrm{~nm}) / \mathrm{Al}$ & 55.86 & 51.96 & 50.62 \\
\hline
\end{tabular}

Moreover, rise in $T_{J}$ for both TP and $600 \mathrm{~nm} \mathrm{ZnO}$ thin film interfaces shows almost similar results for $\geq 350 \mathrm{~mA}$. An increase in $T_{J}$ from $200 \mathrm{~nm}$ to $600 \mathrm{~nm}$ may be due to either higher thermal resistance of $\mathrm{ZnO}$ or surface roughness parameters at higher thickness. The cumulative structure function of $3 \mathrm{~W}$ green LED for five different boundary conditions was recorded as given in Fig. 3. The $R_{\mathrm{th} \text {-tot }}$ of the given LED was measured from the cumulative structure function and the observed values are given in Table -1 . From table -1 , the results measured at $100 \mathrm{~mA}$ reveals the influence of $\mathrm{ZnO}$ interface thickness on $R_{\text {th-tot }}$ as increases with thickness. It also shows high value for $\mathrm{ZnO}$ thickness $\geq 600$ $\mathrm{nm}$. It obeys the conditions of equation 3 where the $R_{\text {effective }}$ increases with BLT increases. The $R_{\text {th-tot }}$ values measured at driving current $\geq 350 \mathrm{~mA}$ shows the behavior of the thermal conductivity of $\mathrm{ZnO}$ thin film with temperature generated as a result of rise in junction temperature. It is attributed to the efficient lateral heat spread of thick $\mathrm{ZnO}$ thin film $(>600 \mathrm{~nm}$ ) than thin $\mathrm{ZnO}(200 \mathrm{~nm})$ at high current density.

Table 1 exhibits that the observed $R_{\text {th-tot }}$ is low $(49.46 \mathrm{~K} / \mathrm{W})$ for $200 \mathrm{~nm} \mathrm{ZnO}$ coated at $700 \mathrm{~mA}$ than other boundary conditions. It is also observed that the $R_{\text {th-tot }}$ is low for $\mathrm{ZnO}$ coated Al substrates compared with TP applied boundary condition. In addition, a small increase in $R_{\text {th-tot }}$ is noticed with increase of $\mathrm{ZnO}$ thickness from $200 \mathrm{~nm}$ to $600 \mathrm{~nm}$. This may be due to the influence of thermal mismatch between $\mathrm{Al}$ substrate and $\mathrm{ZnO}$ at increased temperature. The thermal mismatch is directly proportional to coefficient of thermal expansions (CTE) and temperature difference since Al have high CTE $\left(22.2 \times 10^{-6} / \mathrm{K}\right)$ than $\mathrm{ZnO}\left(2.43 \times 10^{-6} / \mathrm{K}\right)$. At high 
current density, the temperature difference between $\mathrm{Al}$ and $\mathrm{ZnO}$ is high as a result of high $T_{J}$ and hence thermal mismatch stress developed at high current density $(\geq 350 \mathrm{~mA})$. It is evidently proved by observed the difference in $R_{t h}\left(\Delta R_{t h}\right)$ was low for $100 \mathrm{~mA}(1.31 \mathrm{~K} / \mathrm{W})$ than higher driving current $(\geq 350$ $\mathrm{mA})$. It is also observed that $100 \%$ increment in $\Delta R_{t h}$ could be noticed for high driving current for $600 \mathrm{~nm} \mathrm{ZnO}$ thin film coated samples. Normally, the thermal conductivity of polycrystalline material is determined by the grain size and microstructure effects, such as impurity and defect $[12,13]$.

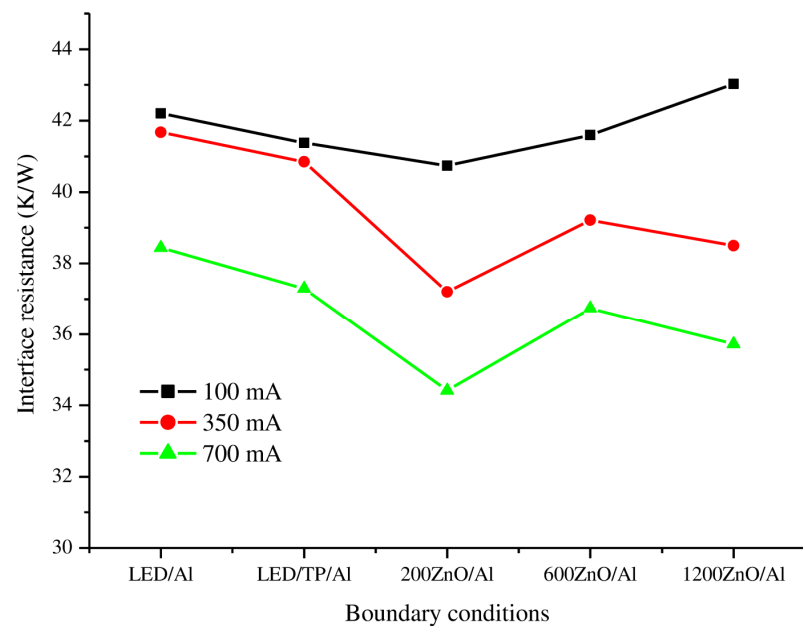

Fig4. Interface thermal resistance of $3 \mathrm{~W}$ green LED for five different boundary conditions measured at various driving currents

Overall, $200 \mathrm{~nm} \mathrm{ZnO}$ coated $\mathrm{Al}$ substrates shows low $R_{\text {th-tot }}$ values for all driving currents. It attributes the influence of BLT on the thermal resistance of the interface material. In order to study the thermal resistance of interface material, the interface resistance is derived from the cumulative structure function analysis (Fig. 3) and the observed interface resistances for different thickness of $\mathrm{ZnO}$ at various driving current are shown Fig. 4. It explains that the interface resistance is low for $200 \mathrm{~nm} \mathrm{ZnO}$ thin film than other thicknesses. Fig. 4 also reveals the influence of driving current on the interface resistance and shows low values for all boundary conditions measured at $700 \mathrm{~mA}$. It clearly indicates that the interface resistance value increase for the film thickness increases from 200 to $600 \mathrm{~nm}$. This may be due to the influence of surface roughness parameters such as step profile of the surface or peak valley distance range. A detailed discussion on this surface roughness parameters are discussed in the consecutive section.

Moreover, a small decrease in resistance could be observed for TP applied boundary condition than bare Al substrate condition. This may be due to the thermal conductivity of interface material (air - $0.024 \mathrm{~W} / \mathrm{m} . \mathrm{K}$ and thermal paste -0.8
$\mathrm{W} / \mathrm{m} . \mathrm{C})$. A decrease in interface resistance of $\mathrm{ZnO}$ thin film is attributed to low thermal conductivity of thermal paste than $\mathrm{ZnO}$ interface $(1-1.2 \mathrm{~W} / \mathrm{mK})$ used in this study. During the burning of LED at high driving current, the temperature of the interface is increased which induces the thermal conductivity and hence the resistance decreases. But the quality of the thin film also influences the thermal conductivity. In our study, the interface resistance is observed as high for thicker film $(\geq 600$ $\mathrm{nm}$ ) than $200 \mathrm{~nm}$. It may be due to the volume of micropore increases with increase in thickness [14] and hence the interface resistance increases.

\subsection{Surface Analysis by AFM}

In order to measure the surface topography, AFM was used to capture the surface images of the bare $\mathrm{Al}$ and $\mathrm{ZnO}$ coated $\mathrm{Al}$ substrates and presented in Fig. 5 (a-d). Fig. 5 a shows the surface image of bare $\mathrm{Al}$ substrate and reveals the rough nature and Fig. 5 (b-d) depicts the surface topography of $\mathrm{ZnO}$ thin film coated $\mathrm{Al}$ substrates for various thickness and also show smooth surface when compared to bare $\mathrm{Al}$ one. From fig. 5, it is easy to understand that the film thickness plays an important role on surface modification. Each fig. parts in Fig.5 have distinct surface which is mainly due to substrate and film thickness variations.

Table2. Surface roughness parameters of $\mathrm{ZnO}$ thin film coated on $\mathrm{Al}$ substrates

\begin{tabular}{|l|c|c|c|c|}
\hline Samples & Bare Al & $\begin{array}{c}200 \mathrm{~nm} \\
\mathrm{ZnO} / \mathrm{Al}\end{array}$ & $\begin{array}{c}600 \mathrm{~nm} \\
\mathrm{ZnO} / \mathrm{Al}\end{array}$ & $\begin{array}{c}1200 \mathrm{~nm} \\
\mathrm{ZnO} / \mathrm{Al}\end{array}$ \\
\hline Roughness $(\mathrm{nm})$ & 34.2 & 5.3 & 13.5 & 11 \\
\hline Grain size $(\mu \mathrm{m})$ & 1.43 & 0.25 & 0.49 & 0.32 \\
\hline $\begin{array}{l}\text { Peak - valley } \\
\text { range }(\mathrm{nm})\end{array}$ & $200-500$ & $25-55$ & $60-145$ & $35-125$ \\
\hline $\begin{array}{l}\text { Max. peak- } \\
\text { valley range } \\
(\mathrm{nm})\end{array}$ & 320 & 40 & 100 & 80 \\
\hline
\end{tabular}

It has been reported that roughness plays an important part in determining the thermal resistance of a contact interface. The influence is positive, i.e., increases the resistance. A twofold increase in roughness can result in a four to fivefold increase in the thermal resistance [15]. 

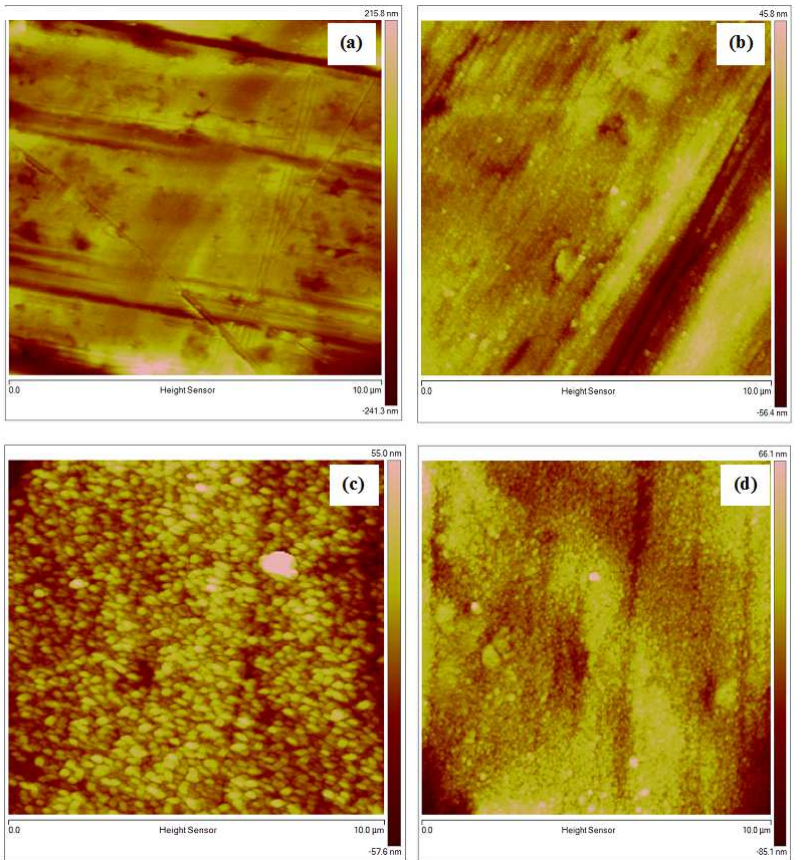

Fig5. AFM images of (a) bare and $\mathrm{ZnO}$ thin film coated $\mathrm{Al}$ substrates at (b) $200 \mathrm{~nm}$, (c) $600 \mathrm{~nm}$ and (d) $1200 \mathrm{~nm}$ thickness
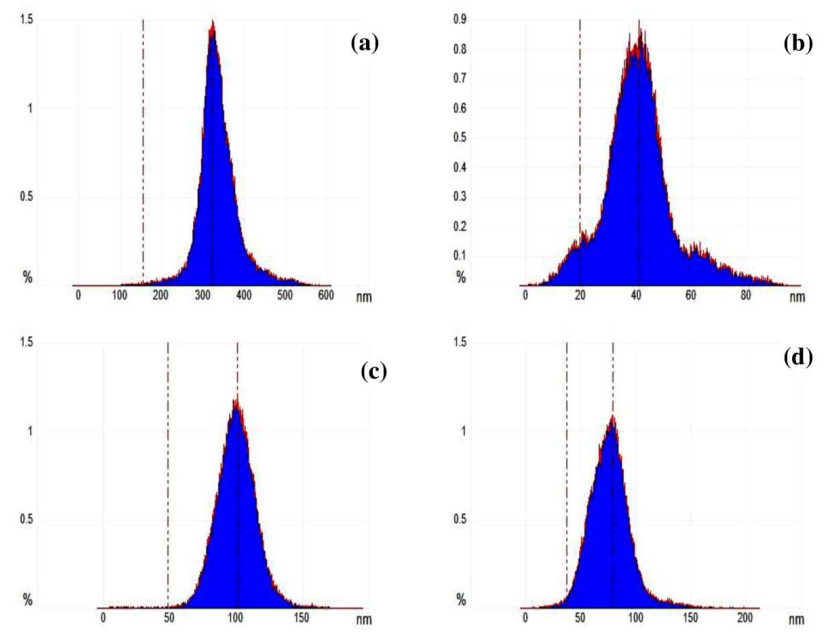

Fig6. Step profile of (a) bare and $\mathrm{ZnO}$ thin film coated $\mathrm{Al}$ substrates at (b) $200 \mathrm{~nm}$, (c) $600 \mathrm{~nm}$ and (d) $1200 \mathrm{~nm}$ thickness.

Consequently, the surface roughness of the all our samples are also measured using software and the observed values are presented in Table -2 . It clearly indicates that the roughness value increases with thickness increases. Among the $\mathrm{ZnO}$ thin film samples, low value in surface roughness could be observed with $200 \mathrm{~nm} \mathrm{ZnO}$ on $\mathrm{Al}$ and hence the LED samples with $200 \mathrm{~nm} \mathrm{ZnO}$ coated $\mathrm{Al}$ substrates show low value in $R_{\mathrm{th}}$ tot than other thicknesses. Moreover, thin film coating gives surface smoothness when it is coated over rough or unpolished surfaces and evidenced by observing low surface roughness values than bare substrate (see fig.5). A noticeable increment in surface roughness could be observed from $200 \mathrm{~nm}$ to 600 $\mathrm{nm} \mathrm{ZnO}$ thin film samples. This could be one of the reasons for huge difference in $R_{\text {th-tot }}$ between 200 and $600 \mathrm{~nm} \mathrm{ZnO}$ thin film samples as stated by Yovanovich et al work [15].
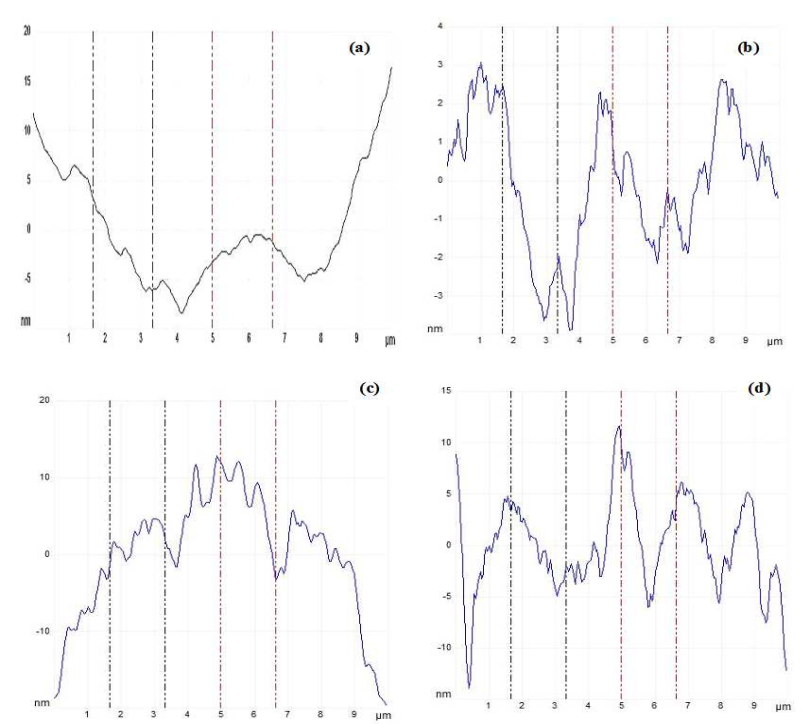

Fig7. Peak-valley distance of (a) bare and $\mathrm{ZnO}$ thin film coated Al substrates at (b) $200 \mathrm{~nm}$, (c) $600 \mathrm{~nm}$ and (d) 1200 nm thickness

In addition, the grain size of $\mathrm{ZnO}$ thin film is also evaluated from AFM images and also given in table -2 . It shows that the grain size increases with thickness increases. According to the ref. [13], the grain size is one of the leading factors which affect the thermal transport which is evidently proved in our studies by observing low $R_{\text {th-tot }}$ and $R_{\text {th-b-hs }}$ for $200 \mathrm{~nm} \mathrm{ZnO}$ thin film than other thickness. Moreover, the thermal contact resistance of $\mathrm{ZnO}$ thin film with large grain size is high compared to thin film with small grain size and hence the 200 $\mathrm{nm} \mathrm{ZnO}$ thin film shows low resistance value than other thickness [14]. It can be seen that the $200 \mathrm{~nm} \mathrm{ZnO}$ thin film show smaller grain size than other two thicknesses (600 and $1200 \mathrm{~nm})$.

The surface step profile study is a scientific approach for the surface analysis in electronic industries. It will give the surface waviness profile of the specified surface under study. It is the measure of the highest peak and deepest valley across the surface profile from the baseline. It clearly represents the contact points on the surface for thermal conductivity [16]. To analyze the surface step profile of the bare and $\mathrm{ZnO}$ thin film coated surface, the AFM images were processed using 
software and observed the surface step profile as given in Fig. 6. It also clearly indicates that the area under the curve indicates the distribution of highest peak and deepest valley across the bare $\mathrm{Al}$ and $\mathrm{ZnO}$ thin film surface. The $\mathrm{X}$ axis shows the percentage of step profile distribution on the surface and shows maximum height of the surface step profile for bare $\mathrm{Al}$ substrate and the range is also between 200 and $500 \mathrm{~nm}$. Fig. 6 also clearly depicts that the peak height and depth valley distribution is low for $200 \mathrm{~nm} \mathrm{ZnO}$ coated $\mathrm{Al}$ substrates than all other $\mathrm{ZnO}$ thicknesses (see table - 2).

From the AFM analysis, it could also be observed that the roughness profile of the surface of bare and $\mathrm{ZnO}$ thin film coated substrates are given in Fig. 7 (a-d). In order to understand the increase of $R_{\text {th-tot }}$ for $600 \mathrm{~nm} \mathrm{ZnO}$ thin film coated $\mathrm{Al}$ substrate in detail, the peak-valley distance analysis is also carried out using the roughness profile of all bare and $\mathrm{ZnO}$ thin film surfaces and the observed results are presented in Table - 2. It clearly indicates that the maximum peak-valley distance is high for $600 \mathrm{~nm} \mathrm{ZnO}$ thin film $(100 \mathrm{~nm})$ than other thicknesses and hence the contact conductance of MCPCB on $600 \mathrm{~nm} \mathrm{ZnO}$ thin films coated $\mathrm{Al}$ substrate is low compared to other thicknesses.

\section{CONCLUSIONS}

$\mathrm{RF}$ sputtered $\mathrm{ZnO}$ thin film was used as TIM for high power LED and tested the thermal resistance of $3 \mathrm{~W}$ green LED at three different $\mathrm{ZnO}$ thicknesses. $200 \mathrm{~nm} \mathrm{ZnO}$ thin film coated Al substrates showed high $\Delta \mathrm{TJ}$ vale of $7.46{ }^{\circ} \mathrm{C}$ at $700 \mathrm{~mA}$ when compared with bare substrate. Low Rth-tot and TJ was evidently proved due to low BLT (200 nm of $\mathrm{ZnO}$ thin film) at interface between MCPCB and heat sink. In addition, heat transport at high rate was also achieved with low surface roughness of $\mathrm{ZnO}$ thin film with smaller particles.

\section{REFERENCES}

[1]. www.assemblyanswers.com/resources/.../TIMResistance-Paper.pdf

[2]. Y. J. Heo, H. T. Kim, S. Nahm, Y. J. Yoon and Y. Kim, Appl. Therm. Eng., 50, 799, (2013).

[3]. J. P. Mathewa, G. Varghese, and J. Mathew, Chin. Phys. B 21, 078104 (2012)

[4]. Y. Xu, X. Luo and D. D. L. Chung, Transactions of the ASME-Journal of electronic packaging 122, 128, (2000).

[5]. S. J. Pearton, D. P. Norton, K. Ip, Y. W. Heo, T. Steiner, Prog. Mater. Sci. 50, 293, (2005).

[6]. B. Roehr, "Mounting Considerations for Power Semiconductors", Motorola Application Note AN1040.

[7]. Catalog \#87-HS-9, pp. 8, Thermalloy Inc., Dallas, TX, 1987.

[8]. S.Shanmugan, D.Mutharasu and H. Abu Hassan, Int. J. Electro. Comp. Sci. Engg., 2, 296, (2012)
[9]. D. Mutharasu, S. Shanmugan, P. Anithambigai, and O. Zeng Yin, IEEE Trans. Elect. Devices, (In press)

[10]. L.S. Fletcher, IEEE Trans. Compon., Hybrids, Manuf. Tech. 13, 1012, (1990).

[11]. D. Blazej, Electronics Cooling; 9, 14, (2003).

[12]. Y-d. Li, De-m. Wang, H. Jin, J-p. Lu, J. Zhou; Effect of film thickness on properties of Al-doped $\mathrm{ZnO}$ film as transparent conducting electrodes in OLEDs, 978-14673-2475-5/12, IEEE proceedings.

[13]. J.Z. Tian, D.J. Yang, C.K. Chen, H. Cheng, P. Hing, J. Appl. Phys. 96, 4563, (2004).

[14]. Z. X. Huang, Z.A. Tang, J. Yu, S. Bai, Physica B 406, $818(2011)$

[15]. M. M. Yovanovich, W. M. Rohsenow; Influence of surface roughness and waviness upon thermal contact resistance, Technical Report No. 6361-48, June 1967, published by Massachusetts Institute of Technology, Cambridge, Massachusetts 02139.

[16]. Application notes, InTech-

Measurement_of_the_nanoscale_roughness_by_atomic _force_microscopy_basic_principles_and_applications. pdf

\section{BIOGRAPHIES:}

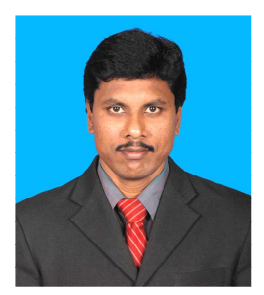

Shanmugan Subramani has received his bachelor degree (1997) in chemistry, diploma in (1998) chemical process instrumentation and Master degree (2000) in Energy Science. He has received his $\mathrm{Ph} . \mathrm{D}$ in the field of thin film solar cells during 2009. He has published more than 65 research papers in the refereed International journals and conferences. He also has a research experience of more than 7 years. Now he is working as a Post Doctoral Research Fellow in School of Physics, University Sains Malaysia upto date. His research is focused on identifying best thermal interface material in solid state devises in semiconductor industries.

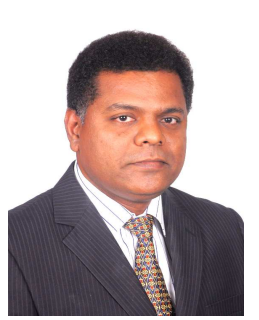

Mutharasu Devarajan holds a master's degree (1991) in Physics and M.Phil (1992) \& PhD (2000) in Energy Sciences (Renewable energy) from Madurai Kamaraj University, India. $\mathrm{He}$ has received the young scientist fellowship awards from Indian National Science Academy (INSA) in 2001 and Tamilnadu State Council for Science and Technology (TNSCST), India in 2002 as recognition to his research in the field of Alternative energy - specialized in solar thermal and photovoltaic technologies. He has published more than 140 research papers in the refereed International journals and conferences. He has a teaching and research experience of more than 20 years. Currently, he is working as Associate Professor with school of 
physics, USM, Penang, Malaysia. His research interests include heat transfer in semiconductors and materials characterization.

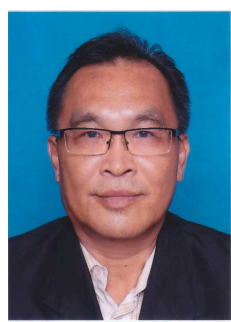

Haslan Abu Hassan was born in Malacca, Malaysia in 1960. He received the B.Sc. degree in Physics from the University of East Anglia, United Kingdom in 1983, and the M.Sc. and Ph.D. degrees from the University of Essex, United Kingdom in 1984 and 1987, respectively, for the study of excitations in semiconductor superlattices. He has been with the School of Physics, Universiti Sains Malaysia, Penang, Malaysia, since 1987, and was the Dean of the School of Physics from 2005 to 2010. Professor ABU HASSAN is currently serving as the Director of the Centre for Education and Training in Renewable Energy, Energy Efficiency and Green Technology (CETREE\&GT), Universiti Sains Malaysia. His research interests include thin films of III-V nitrides for laser diodes and solar cells, nanowires of $\mathrm{GaN}$ as solar cells, surface phonon polaritons from nitride interfaces and thermoelectric materials from chalcogenides 